\title{
Everything Under My Control: CEO Characteristics and the Evaluation of Middle Manager Performance in Small and Medium-Sized Firms
}

\author{
Nora Haas $^{1}$ - Gerhard Speckbacher ${ }^{1}$
}

Received: 9 September 2015 / Accepted: 11 January 2017 / Published online: 24 January 2017

(C) The Author(s) 2017. This article is available at SpringerLink with Open Access.

\begin{abstract}
Studies of small and medium-sized enterprises have provided evidence that CEOs of such firms can have a dominating influence on firm activities. Drawing on upper echelons theory, we analyze the influence of CEO personality (CEO internal locus of control), CEO ownership and CEO education on the evaluation of middle manager performance. In line with our expectations, we find evidence for a direct effect of CEO ownership (negative) and CEO education (positive) on the use of objective performance evaluations and for a direct effect of the CEO's internal locus of control on the use of subjective performance evaluations. Moreover, we provide evidence for a moderating role of both CEO ownership and education with respect to the influence of the CEO's locus of control on the use of subjective evaluations. We use a sample of 247 small and medium-sized manufacturing firms to test our hypotheses.
\end{abstract}

Keywords Small and medium-sized Enterprises $\cdot$ CEO personality $\cdot$ Performance evaluations

\section{JEL Classification M12}

\section{Introduction}

The CEO has the primary responsibility for defining a firm's strategic directions and goals as well as for guiding and regulating the actions of middle and lower

G. Speckbacher

Gerhard.Speckbacher@wu.ac.at

1 Institute of Strategic Management and Management Control, WU Vienna University of Economics and Business, Welthandelsplatz 1, 1020 Wien, Austria 
level managers who execute firm strategy (e.g. Calori et al. 1994). The powerful, sometimes even dominating influence of CEOs on firm activities (particularly in relatively small firms) has prompted enormous interest in the impact of CEO personality on strategic behaviors and the study of CEO personality has emerged as an important topic in management research (Chatterjee and Hambrick 2007; Chin et al. 2013; Crossland et al. 2014; Herrmann and Nadkarni 2014; Hiller and Hambrick 2005). Most existing studies in upper echelons research have focused on the influence of CEO personality characteristics on a firm's strategic choices (Carpenter et al. 2004; Hambrick 2007), while their long proposed influence on a firm's major administrative choices (see Hambrick and Mason 1984, p. 195) has received less attention. Recently, an emerging literature in accounting research has suggested an influence of managers' personal caracteristics on their accounting decisions (e.g. Bamber et al. 2010; Ge et al. 2011). However, among these studies only very few focus on management control system (MCS) choices and "theoretical insights and empirical findings about the relevance of top executives in designing, perceiving and using MCS are still rare" (Schaeffer and Dossi 2014, p. 219).

Hiebl's (2014) recent review of upper echelons theory in management accounting and control research includes only three studies with regard to the relationship between CEO characteristics and management accounting choices (these are: Abernethy et al. 2010; Burkert and Lueg 2013, and Naranjo-Gil and Hartmann 2007). Abernethy et al. (2010, p. 3) motivate their study claiming that it is also "the behavioral tendencies and personal traits associated with a leader that influence how they use controls to influence the behavior of subordinates". However, the study itself does not refer to trait theories of leadership but rather analyzes how a leader's leadership behaviors (initiating structure vs. considerate leadership) are associated with the way how this leader controls subordinates. Rather than measuring leaders' personality characteristics and traits, Abernethy et al. $(2010$, p. 4) argue that "Leadership style captures cognitive or personality characteristics of managers". According to the existing literature on leadership, the association between personality characteristics (leader traits) and leadership styles (i. e. leader behaviors), however, is unclear and this literature has even treated leader traits and behaviors as independent variables to explain leader effectiveness. ${ }^{1}$ Thus, the study by Abernethy et al. (2010) can only speculate about the association between leader personality characteristics and Management Control choices. The other two studies focus on so-called observable CEO characteristics. Upper echelons research has interpreted observable CEO characteristics (such as age, tenure, functional background or education) as proxies for "psychological constructs" that directly measure aspects of personality (but are much more difficult to obtain, see Carpenter et al. 2004). While Burkert and Lueg (2013) do not find a significant impact of CEO characteristics on valuebased management systems, Naranjo-Gil and Hartmann (2007) compare hospitals with CEOs having a business-related education background versus a more clinical background and they find that the former make more use of financial information, use control systems more diagnostically and put greater emphasis on performance

\footnotetext{
${ }^{1}$ On behavioral vs. trait theories of leadership and possible associations between the two, see e. g. Derue, Nahrgang, Wellman and Humphrey (2011).
} 
evaluation while the latter focus more on non-financial information and use control systems more interactively.

Observable CEO characteristics have also been used to explain the particular characteristics of small and family businesses - without explicitly using an upper echelons theory perspective, however. This literature has pointed at CEO ownership (the CEO not only leads the firm but also owns firm shares) and CEO education as two characteristics to influence the administrative choices of small and mediumsized firms (see Daily and Dollinger 1992; Hiebl et al. 2015; Lavia López and Hiebl 2015; Speckbacher and Wentges 2012). We build on this literature and analyze how CEO ownership and education are associated with the evaluation of middle manager performance.

The main contribution of this paper, however, focuses on a psychological construct, the CEO's internal locus of control, to explain variation in the use of subjective performance evaluations. Psychological constructs have rarely been used so far in management control research and the studies that employ such constructs use them to explain variation in employees' reaction to control systems rather than explaining their possible impact on the choices of those who design control systems. For example, a recent paper by Young, Du, Dworkis and Olsen (2016) investigates how employee narcissism impacts the effectiveness of control systems. Two classical studies by Brownell $(1981,1982)$ find that the locus of control of subordinates determines the effects of budgetary participation.

In upper echelons research, CEO locus of control has become a main psychological construct besides CEO narcissism and CEO core self-evaluation (see Herrmann and Nadkarni 2014; key examples of such studies are Boone et al. 1996; Miller et al. 1982).

We believe that the CEO's internal locus of control is particularly interesting for explaining control choices in small and medium-sized firms, since there is broad evidence that small and mediums-sized firms are often dominated by an "omnipresent" CEO, who tries to keep the whole firm under his/her control, exerting an immediate influence on strategy development as well as on strategy implementation (Harris et al. 1994; Mintzberg and Waters 1982; Ward 1988). In its original interpretation by Rotter (1954), the "internal locus of control" (iLOC) construct measures the extent to which individuals believe to be in control over their life situation and to what degree they trust in their own capacity to influence their environment. According to Lied and Pritchard (1976) and Phares (1976) this construct measures how confident individuals are about their own ability to assess and to influence others' behavior.

Since subjective performance evaluations, i. e. the use of personal judgments and assessments to evaluate subordinates' overall conduct, are by definition subjective assessments of others' behaviour with the purpose of influencing this behaviour, it seems reasonable that the internal locus of control can contribute to explaining the use of such evaluations. Research in psychology supports the notion that a rater's psychological characteristics might influence the use of subjective ratings. In fact, previous research in psychology has found that a rater's conscientionsness and agreeableness influence the biases in subjective ratings of performance (Bernardin et al. 2000; Goldberg 1992), without, however, analyzing the influence of the rater's locus of control on the use of such subjective ratings. 
In the following, we theorize on how a CEO's personal characteristics are associated with his/her use of objective and subjective performance evaluations. In line with findings from previous literature, we propose that CEO ownership and education contribute to explaining variation in the use of objective performance evaluations. With respect to the use of subjective performance evaluations, our theoretical deliberations on the the internal locus of control construct lead us to propose a direct effect of the CEO's iLOC on the use of SPE and a role of both CEO ownership and CEO education in moderating this relationship.

\section{Hypothesis Development}

\subsection{CEO Characteristics And The Use Of OPE}

We know from prior contingency-based management accounting research (Chenhall 2003; Hall 2016) that the operating context of organizations influences the extent to which pre-defined financial and nonfinancial measures such as revenues, profit or customer satisfaction are used for performance evaluation (objective performance evaluations, OPE). According to this research, OPE are used to greater extent, when outcomes are easily measured, tasks are less programmable and when firm size increases (Chenhall 2003).

Beyond these long-discussed organizational contingencies, small business and family firm literature (Daily and Dollinger 1992; Hiebl et al. 2015; Lavia López and Hiebl 2015; Speckbacher and Wentges 2012) has pointed at CEO firm ownership and CEO education as two CEO-related characteristics that influence administrative choices in relatively small firms. According to Daily and Dollinger (1992), the separation of ownership and management implies that owners are absent from daily business and these "outside" owners "will insist on the use of formal measures in order to protect their investments" (Daily and Dollinger 1992, p. 124). Therefore, CEOs who are no firm-owners (separation of ownership and control) are likely to experience a higher pressure to justify their actions towards owners and to use more formalized measures and performance evaluation practices. Since the use of predefined financial and nonfinancial performance measures for the evaluation of middle-manager performance can be interpreted as a "formal mode of management" that signals professionalism to owners (see Speckbacher and Wentges 2012, p. 43), non-owner CEOs are expected to make more use of such formal evaluation practices.

H1a. CEOs who are owners of the company make less use of objective performance evaluations.

According to a common line of argument in the literature on small and mediumsized enterprises, CEOs in smaller firms tend to show a lack of professionalism, i. e. a lack of knowledge of established practices such as OPE practices (see e. g. Daily and Dollinger 1992; Speckbacher and Wentges 2012). In particular, the combined use of financial and nonfinancial performance measures in performance evaluation has become a widely proposed (best) practice but even many large firms seem to have difficulty in implementing such performance management systems (see e.g. 


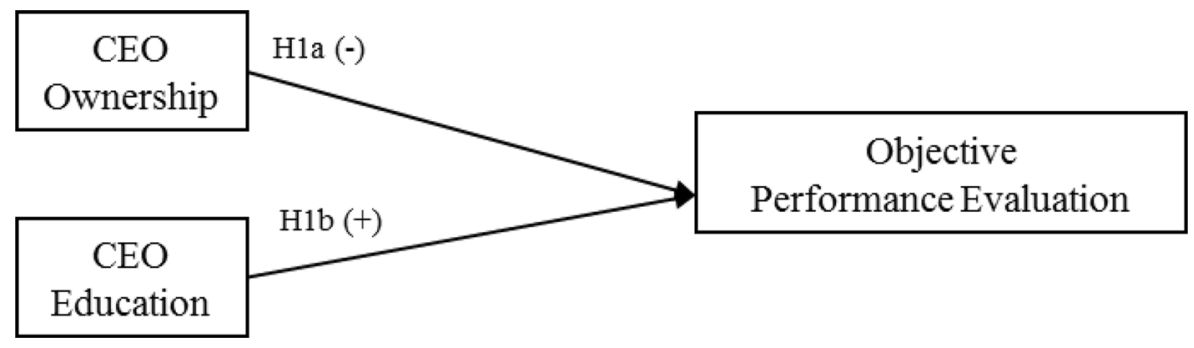

Fig. 1 Structure of the hypothesized relationships H1ab

Speckbacher et al. 2003). Upper echelons theory has argued that firms whose top managers have a higher level of education and management training might be "more complex administratively" (Hambrick and Mason 1984, p. 201).

Therefore, it seems reasonable that CEOs with lower education will be more likely to abstain from using objective performance evaluation practices that include both financial and nonfinancial performance indicators (OPE) (Fig. 1).

H1b. CEOs with higher education make more use of objective performance evaluations.

\subsection{CEO Characteristics And The Use Of SPE}

While objective performance evaluations are based on formal pre-defined measures, subjective performance evaluations are more ambiguously structured. When applying subjective performance evaluations, it is relatively ambiguous which (qualitative) criteria are to be used and how assessments can be made. In contrast to objective performance evaluations which rely solely on ex-ante defined indicators, subjective performance evaluations are based on the manager's personal impressions, feelings and opinions (Bol 2008; Gibbs et al. 2004) and subjective performance measures are a "superior's subjective judgments about qualitative performance indicators" (Moers 2005, p. 68). According to Bol (2008, p. 2), subjectivity "entails judgment based on personal impressions, feelings, and opinions, rather than on external facts". Typically, subjective evaluations refer to performance dimensions that are not directly related to the task and, therefore, subjective evaluations have been specified as "assessments of non-task-related performance" (Grabner and Speckbacher 2016). In contrast to objective performance evaluations, subjective assessments allow the evaluator to exploit and incorporate any information that arises during the measurement period if this information seems relevant for the assessment (Gibbs et al. 2004). Moreover, subjective assessments allow the evaluator to incorporate difficultto-measure dimensions. In situations that are ambiguously structured, personality can be expected to have a relatively strong influence on behaviour (Cooper and Withey 2009; Mischel 1977). In line with this argumentation, subjective performance assessments (in contrast to more clearly structured and formalized objective performance evaluations) have been argued to be more influenced by psychologybased factors than by "economic facts" (Ittner et al. 2003). 
The "internal locus of control" (iLOC) construct measures to what extent individuals believe to be in control over their life situation and to what degree they trust in their own capacity to influence their environment (Rotter 1954). According to Lied and Pritchard (1976) and Phares (1976), the iLOC construct is considered a measure of individuals' confidence in their own ability to assess and to influence others' behavior. Therefore, it seems reasonable to assume that CEOs with a high iLOC are more likely to make use of subjective performance assessments in order to regulate subordinate behavior. Furthermore, it has been proposed that individuals with a relatively high iLOC tend to show a more extensive information-search behavior (Srinivasan and Tikoo 1992), they tend to consider more diverse information in complex task situations (Spector 1982, p. 488), and it has been argued that CEOs with a more internal locus of control show higher openness to new methods of service and production (Miller et al. 1982). Using qualitative subjective measures in performance assessments can be interpreted as an attempt to incorporate more indicators that cannot be readily measured, such as team-working abilities or loyalty, into performance assessments (Bol 2008; Gibbs et al. 2004). As subjective performance evaluations hand over power to the evaluators (Prendergast 1993), they also support the disposition of "high iLOC individuals" to have things under their own control (Phares 1976).

Overall, we hypothesize that a higher iLOC of CEOs will be associated with a more intensive use of subjective evaluations of middle manager performance.

H2a. CEOs with a more pronounced internal LOC make more use of subjective performance evaluations.

Literature on small and medium-sized firms has argued for a long time that CEOs who also hold firm shares (owner CEOs) have more discretion to put forward their own ideas and plans and that they have a more direct influence on strategy development and implementation than (professional) outside managers (Harris et al. 1994; Mintzberg and Waters 1982; Ward 1988). In fact, upper echelons theory has pointed to equity ownership as an aspect of "managerial discretion" which is argued to intensify the influence of executives' psychological characteristics on their strategic and administrative decisions (Hambrick, 2007; Hambrick and Finkelstein 1987; Finkelstein et al. 2009; Finkelstein and Peteraf 2007). For CEOs with a dual role as managers and owners personal characteristics can thus be expected to have a stronger influence on control system design (see also Hiebl 2014, p. 235).

Thus, we expect the positive relationship between the CEO's internal LOC and the use of subjective performance evaluations to be stronger for firms where CEOs are equity owners than for firms with professional outside CEOs who do not possess firm shares.

H2b. The association between the CEO's internal LOC and the use of subjective performance evaluations is stronger when CEOs are firm owners.

Individuals' level of education is associated with their cognitive styles, their ways of thinking, and their self-control (e. g. Mitchell 2000; Sassi et al. 2009). Upper echelons research has used the level of education as a main observable upper echelon characteristic that predicts executive strategic behavior (e. g. Hambrick and Mason 
1984). In particular, it has been argued that executives' education level affects the comprehensiveness of decision-making processes (see Papadakis and Barwise 2002, Carpenter et al. 2004). A higher level of education can be interpreted as a "regulating mechanism" which leads individuals to invest more time into information search activities and more comprehensive decision-making processes, leaving aside affectations and personal views in decision-making. In fact, existing evidence suggests that CEO education level might attenuate the influence of psychological characteristics such as iLOC on strategic orientations and behaviors (Okhomina 2010a, 2010b). Similarly, a higher education level may attenuate the influence of the CEO's iLOC on the use of subjective performance evaluations.

Moreover, education can influence a person's perception of a task's difficulty and complexity. Hambrick, Finkelstein and Mooney (2005) build on organization behavior and organization psychology research (e. g. Janssen 2001; Karasek 1979) and they define executive job demands "as the degree to which a given executive experiences his or her job as difficult or challenging" (Hambrick et al. 2005, p. 473). For a given task, executives might have differing perceptions on task demands. In general, less educated and trained CEOs may perceive a given job as more demanding than CEOs with better training and education. Since "executives who are under great job demands take mental shortcuts and engage in limited search to arrive at their choices" (Hambrick et al. 2005, p. 478), higher perceived demands imply a stronger influence of executive personal characteristics on their choices (see also Hiebl 2014, . 237). This line of reasoning thus further supports the above expectation of a stronger influence of the CEO's iLOC as a psychological CEO characteristic on the decision to use subjective performance evaluations.

Overall, we hypothesize that for CEOs with higher education (university degree) the relationship between the CEO's internal locus of control and the use of subjective performance evaluations will be weaker (Fig. 2).

H2c. The association between the CEO's internal LOC and the use of subjective performance evaluations is weaker for CEOs with higher education.

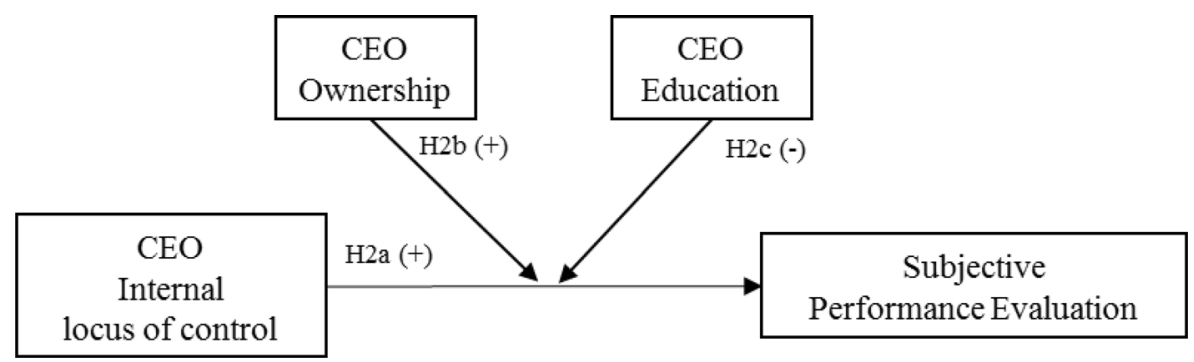

Fig. 2 Structure of the hypothesized relationships H2abc 


\section{Methods And Data}

\subsection{Data Collection}

An online questionnaire was sent to the CEOs of 1.026 manufacturing companies in Austria with more than 50 but less than 250 employees according to the Amadeus database. The mail addresses of the CEOs were hand-collected by scanning the homepages of firms. Our first email was followed up by two reminder emails, leaving us with a final total of 247 usable questionnaires (24\% response rate). In an accompanying letter and in the questionnaire itself we stressed repeatedly that the survey had to be answered only by the CEO personally and no other person within the company should answer it. CEOs answered questions on the psychological variables (the CEO's internal locus of control) as well as questions about their use of mechanisms for evaluating middle manager performance and about other firmrelated variables.

Wherever possible, our survey questions are based on established measures. If there was only an English version of the original construct available, it was translated into German (the whole process was monitored by a language expert).

Since it is difficult to obtain reliable data from relatively small firms who are often unwilling to disclose information on firm characteristics (e.g. Handler 1989) and since our questionnaire also contained various (very personal) questions on the CEO's psychological characteristics, we relied on an extensive pretest with five CEOs of relatively small firms and three consultants who specialize in projects with small and medium-sized enterprises. Based on their comments we slightly reworded several questions and we decided to condense our questionnaire by eliminating questions to increase the likelihood of a satisfactory response rate. For those (control) variables where our interviews during the pretest verified that CEOs and experts (consultants) easily understood the underlying questions and shared our interpretations and understanding of the formulations, we decided to rely on reduced or even single-item scales.

As pointed out by previous research (e. g. Speckbacher and Wentges 2012), data from the Amadeus Database is not always reliable with respect to employee numbers and, therefore, we included a question on employee numbers in our questionnaire. Where we noticed major deviations, we double-checked for the correct numbers from available sources (webpages) or contacted firms to find out the correct numbers. Because of several fast growing firms, the actual number of employees in several cases was much higher than reported in the Database.

We checked the likelihood of non-response bias by comparing early to late respondents using study variables as suggested by Armstrong and Overton (1977) and found no significant mean differences between early and late respondents except for one item within our Locus of Control construct. ${ }^{2}$ In addition, we gathered in-

\footnotetext{
2 The item is "Whether or not I have a car accident depends mainly on my driving talent". We recalculated all the regression analyses excluding this item from the respective construct. These analyses showed the same results with only slight changes with respect to the $p$-values (iLOC significant at $p=0.021$ instead of $p=0.08)$.
} 
formation on firm characteristics, e.g. employee numbers or number of recorded shareholders, for all firms in our initial sample. We compared such data from nonrespondents with the data provided by respondents, as recommended, for example, by Celly and Frazier (1996), and, again, uncovered no significant differences. To avoid common method bias, we framed our research project in a neutral way ("cover story") to psychologically separate the formulations of personality items from the management control items (use of objective/subjective evaluations) as our dependent variable. To check for possible common method bias, we employed Harman's single-factor test (Podsakoff et al. 2003) and did not find any indication of such bias. Moreover, we checked for multicollinearity and discovered no indication of multicollinearity issues.

For the list of employed constructs please see the appendix.

\subsection{Measurement Of Variables}

\subsubsection{CEO Characteristics}

The main CEO psychological characteristic "internal locus of control" (iLOC) was measured using the German version of the internality scale of Levenson (1972), which is a reconceptualization of Rotter's (1954) original locus of control measure, translated by Krampen (1980). Levenson's version avoids problems of Rotter's scale such as social desirability bias and the forced-choice response setting, where external and internal control expectancies were strictly distinguished (Lefcourt 1991 cited in Judge et al. 1999; Krampen 1980; Hodkinson 1992). In all items, the first person was used in order to stress the reference to the CEO as our target respondent. Items include, for instance, "When I have plans I am sure that the planned will be turned into reality" and "I am able to determine a lot of what happens in my life by myself". The scale has been used by other researchers such as Taylor (2010), Hoffman, Novak, Schlosser (2003), Judge et al. (1999) and Waldersee and Sheather (1996). Our pretest indicated severe concerns with three items of the original scale in terms of suitability for CEOs and these items were therefore excluded from the final questionnaire. Hence, in total, five items from the original scale were used. The relatively low Cronbach's alpha (0.625) is not uncommon for psychological constructs of this type and similar to the Cronbach's alpha of 0.66 for this construct reported by Judge et al. (1999).

CEOs were also asked whether they passed through higher education (EDUCATION) which we measured as a dummy variable that has the value of 1 when the CEO has a University degree and the value of 0 otherwise. ${ }^{3}$

Also for measuring whether the CEO possesses firm shares (OWNER) we used a dummy variable with the value 1 when the CEO owns firm shares and 0 where the CEO does not own shares.

\footnotetext{
3 Other studies in management accounting research have used more specific aspects of the educational background (e. g., Naranjo-Gil and Hartmann, 2007; Burkert and Lueg, 2013).
} 


\subsubsection{Subjective and Objective Performance Evaluations}

The CEOs were asked to what extent certain statements are appropriate concerning their application of subjective or objective performance evaluations when evaluating the performance of middle managers. The formulation of items can be found in the appendix. The measurement instruments used have been previously employed in similar form, for example, by Grabner (2014), Grabner and Speckbacher (2016) and Hartmann, Naranjo-Gil and Perego (2010).

\subsubsection{Control Variables}

Since there is persuasive evidence that company size, environmental uncertainty, output measurability and task programmability are organizational contingencies that influence performance measurements practices (see e.g. Chenhall 2003), we added these four variables as control variables. Company size is measured by the number of employees (COMPANY SIZE).

For environmental uncertainty we use a perceptual measure (ENVIRON. UNCERTAINTY) proposed by Moers (2006). Our measures of outcome measurability (OUTCOME MEASURABILITY) and task programmability (TASK PROGRAMMABILITY) rely on Snell (1992). Also a firm's strategic focus on cost leadership has been argued to be a possible influencing factor of performance measurement and we drew on Auzair and Langfield-Smith (2005) and Chenhall and Langfield-Smith (1998) to measure the firm's strategic focus on cost leadership (STRATEGY). The formulation of items can be found in the appendix.

Moreover, we asked for the age of the company (AGE COMPANY) (for its possible influence on performance measurement see e.g. Chenhall 2003). CEOs were also asked for their tenure (measured by the number of years) with the current position (TENURE) as well as whether or not they are founders of the company (FOUNDER).

Detailed results on factor analyses and on the Cronbach's alphas can be found in the appendix. Table 1 shows the correlations of variables.

\section{Results}

Table 2 shows that CEO ownership and education significantly influence the use of OPE. Where the CEO is also owner of equity shares, OPEs are used to a lesser extent. CEOs with a university degree use OPEs more intensively. Thus, hypotheses 1a ( $\beta=$ $-0.19, p=0.003)$ as well as $1 \mathrm{~b}(\beta=0.19, p=0.001)$ are supported.

It is worth mentioning that the CEO's iLOC does not influence the use of OPEs. This supports our argumentation that the influence of psychological CEO characteristics is relevant for ambiguously structured control mechanisms while such an influence is not expected for formalized and more clearly structured control mechanisms such as OPE. 


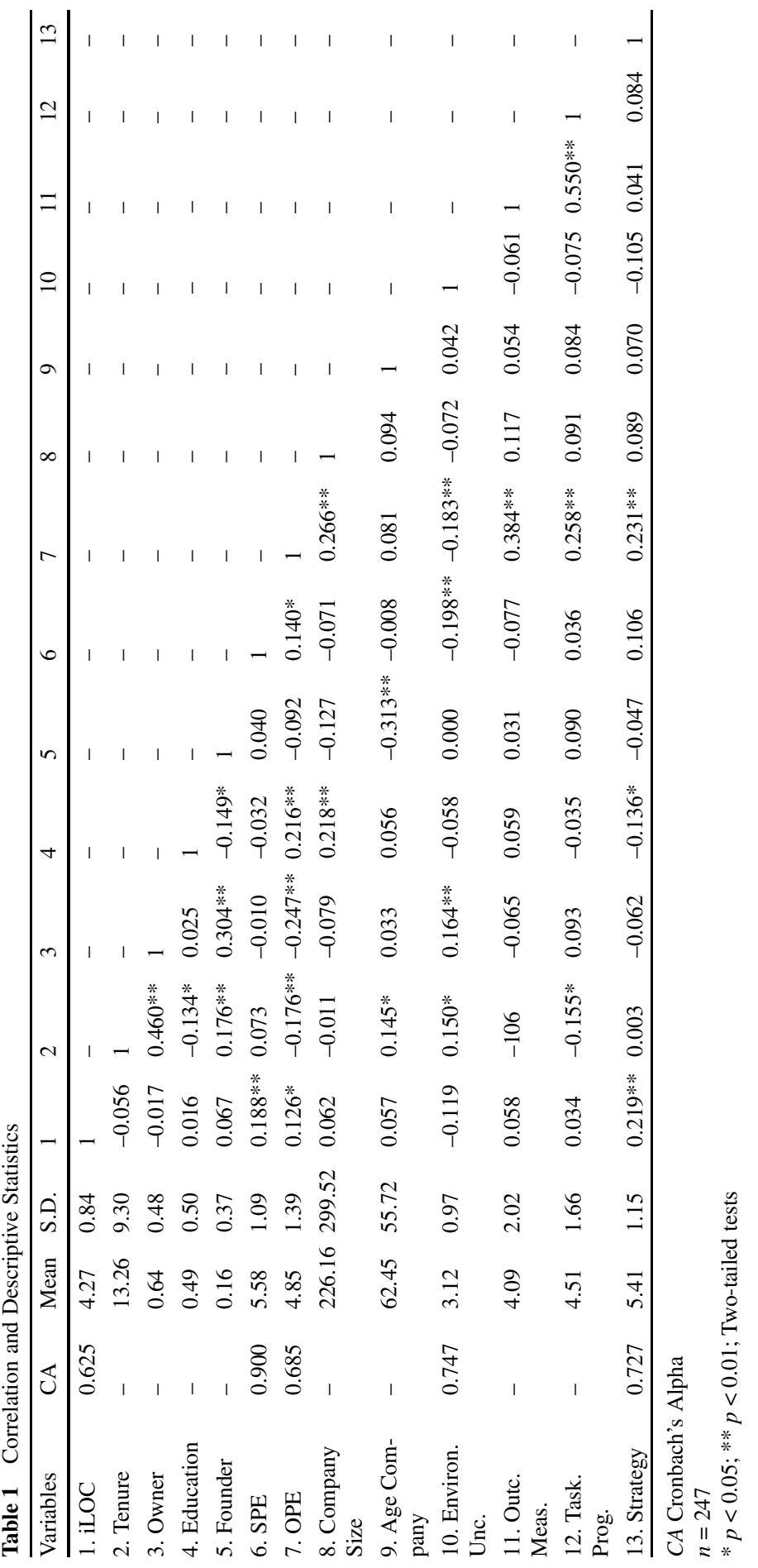


Table 2 Results of regression analysis: Objective performance evaluation

\begin{tabular}{|c|c|c|}
\hline \multicolumn{3}{|c|}{ Dependent variable: Objective performance evaluation } \\
\hline Independent Variables & Model 1 & Model 2 \\
\hline Company Size & $0.20 * *(0.10) 0.001$ & $0.14 *(0.09) 0.012$ \\
\hline Age Company & $0.04(0.00) 0.539$ & $0.04(0.00) 0.481$ \\
\hline Environ. Uncertainty & $-0.13 *(0.08) 0.024$ & $-0.08(0.08) 0.139$ \\
\hline Outcome Measurability & $0.33 * * *(0.05) 0.000$ & $0.31 * * *(0.04) 0.000$ \\
\hline Task Programmability & $0.03(0.06) 0.622$ & $0.03(0.05) 0.613$ \\
\hline Strategy & $0.18 * *(0.07) 0.001$ & $0.20 * * *(0.07) 0.000$ \\
\hline Tenure & - & $-0.02(0.01) 0.757$ \\
\hline Founder & - & $0.02(0.23) 0.696$ \\
\hline Owner & - & $-0.19 * *(0.18) 0.003$ \\
\hline Education & - & $0.19 * *(0.16) 0.001$ \\
\hline iLOC & - & $0.03(0.09) 0.550$ \\
\hline F-value & $13.606 * * * 0.000$ & $10.180 * * * 0.000$ \\
\hline $\mathrm{R}^{2}$ & 0.25 & 0.32 \\
\hline Adjusted $\mathrm{R}^{2}$ & 0.24 & 0.29 \\
\hline
\end{tabular}

$n=247, \beta$ coefficients, standard errors in parentheses, $p$-value estimates in italics ${ }^{+} p<0.1, * p<0.05, * * p<0.01$, *** $p<0.001$, two-tailed tests

As predicted by standard contingency theory, company size and outcome measurability have a positive influence on the use of OPE. Moreover, as expected, firms with a strategic focus on cost leadership make more use of OPE.

Table 3 provides evidence that Hypothesis $2 \mathrm{a}$ is supported $(\beta=0.17, p=0.008)$, i. e. the CEO's iLOC is associated with a more intense use of subjective performance evaluations. Also CEO tenure is positively associated with the extent to which SPEs are used $(\beta=0.14, p=0.058)$.

Model 2 in Table 3 includes the two moderator terms. Both education $(\beta=-0.67$, $p=0.048)$ and ownership $(\beta=0.61, p=0.073)$ seem to moderate the underlying relationship, albeit in different directions, thus providing support for hypotheses $2 \mathrm{~b}$ and $2 \mathrm{c}$.

\section{Discussion}

Literature on small and medium-sized firms has argued that such firms are often dominated by an "omnipresent" CEO, who keeps the whole firm under his/her control (Harris et al. 1994; Mintzberg and Waters 1982; Ward 1988). We contribute to a better understanding of the role of CEO personality in small and mediumsized enterprises by focusing on a psychological characteristic of CEO personality, the internal locus of control (iLOC). The iLOC construct is a measure for the extent to which individuals believe to be in control over their fates and over their environment and how confident individuals are about their own ability to assess and to influence others' behavior (Rotter 1954; Lied and Pritchard 1976; Phares 1976). In line with our expectation, our empirical results show that a pronounced iLOC of CEOs in fact is associated with more use of informal judgments about 
Table 3 Results of regression analysis: Subjective performance evaluation

\begin{tabular}{|c|c|c|c|c|}
\hline \multicolumn{5}{|c|}{ Dependent variable: Subjective performance evaluation } \\
\hline Independent Variables & Model 1 & Model 2 & Model 3 & Comparison \\
\hline Company Size & $\begin{array}{l}-0.09(0.09) \\
0.174\end{array}$ & $\begin{array}{l}-0.10(0.09) \\
0.132\end{array}$ & $\begin{array}{l}-0.10(0.09) \\
0.121\end{array}$ & - \\
\hline Age Company & $\begin{array}{l}0.00(0.00) \\
0.986\end{array}$ & $\begin{array}{l}-0.03(0.00) \\
0.672\end{array}$ & $\begin{array}{l}-0.03(0.00) \\
0.574\end{array}$ & \\
\hline Environ. Uncertainty & $\begin{array}{l}-0.20 * * \\
(0.07) 0.002\end{array}$ & $\begin{array}{l}-0.19 * *(0.07) \\
0.003\end{array}$ & $\begin{array}{l}-0.19 * *(0.07) \\
0.002\end{array}$ & \\
\hline Outcome Measurability & $\begin{array}{l}-0.13^{+}(0.04) \\
0.074\end{array}$ & $\begin{array}{l}-0.14^{+}(0.04) \\
0.058\end{array}$ & $\begin{array}{l}-0.13^{+}(0.04) \\
0.088\end{array}$ & \\
\hline Task Programmability & $\begin{array}{l}0.10(0.05) \\
0.207\end{array}$ & $\begin{array}{l}0.12(0.05) \\
0.119\end{array}$ & $\begin{array}{l}0.12(0.05) \\
0.106\end{array}$ & \\
\hline Strategy & $\begin{array}{l}0.09(0.06) \\
0.152\end{array}$ & $\begin{array}{l}0.05(0.06) \\
0.407\end{array}$ & $\begin{array}{l}0.04(0.06) \\
0.550\end{array}$ & \\
\hline Tenure & - & $\begin{array}{l}0.14^{+}(0.00) \\
0.058\end{array}$ & $\begin{array}{l}0.16 *(0.00) \\
0.032\end{array}$ & \\
\hline Founder & - & $\begin{array}{l}-0.01(0.21) \\
0.920\end{array}$ & $\begin{array}{l}-0.01(0.21) \\
0.857\end{array}$ & \\
\hline Owner & - & $\begin{array}{l}-0.04(0.17) \\
0.592\end{array}$ & $\begin{array}{l}-0.63^{+}(0.75) \\
0.059\end{array}$ & \\
\hline Education & - & $\begin{array}{l}0.02(0.14) \\
0.810\end{array}$ & $\begin{array}{l}0.66 *(0.72) \\
0.047\end{array}$ & \\
\hline iLOC & - & $\begin{array}{l}0.17 * *(0.08) \\
0.008\end{array}$ & $\begin{array}{l}0.13(0.15) \\
0.239\end{array}$ & \\
\hline iLOC*Owner & - & - & $\begin{array}{l}0.61^{+}(0.17) \\
0.073\end{array}$ & \\
\hline iLOC*Education & - & - & $\begin{array}{l}-0.67 *(0.17) \\
0.048\end{array}$ & \\
\hline F-value & $2.926 * * 0.009$ & $2.583 * 0.004$ & $2.695 * 0.001$ & $3.065 * 0.049$ \\
\hline $\mathrm{R}^{2}$ & 0.07 & 0.11 & 0.13 & 0.02 \\
\hline Adjusted $\mathrm{R}^{2}$ & 0.05 & 0.06 & 0.08 & 0.01 \\
\hline
\end{tabular}

$n=247, \beta$ coefficients, standard errors in parentheses, $p$-value estimates in italics

${ }^{+} p<0.1, * p<0.05, * * p<0.01, * * * p<0.001$, two-tailed tests

qualitative, non-task-related performance dimensions such as loyalty, commitment, and quality of work-results with the purpose of influencing subordinate behavior (subjective performance evaluations, see e.g. Bol 2008; Gibbs et al. 2004; Grabner 2014; Grabner and Speckbacher 2016; Moers 2005).

Besides providing evidence for the association of the CEO's iLOC with the use of subjective performance evaluations, we analyze the direct and indirect role of two observable CEO characteristics, CEO ownership and CEO education, in explaining performance evaluations in small and medium-sized firms. Both CEO characteristics have been analyzed in previous literature. In line with previous literature on small and medium-sized firms and building on upper echelons arguments, we interpret CEO ownership as a measure for the CEO's discretion ("latitude of action") and CEO education as a measure for the CEO's professionalism (the extent to which the CEO is aware of and prepared to apply common practices and professional 
methods). In line with this interpretation (and in line with theoretical views and empirical results in previous literature on small and medium-sized firms), we find a direct effect of CEO ownership (negative) and CEO education (positive) on the use of objective performance evaluations.

In contrast to OPE, we do not interpret SPE as a commonly used practice that indicates high professionalism. Moreover, subjective performance measures are of very limited use for non-owner CEOs to justify their actions towards owners. Therefore, we do neither propose a negative effect of CEO ownership (interpreted as CEO discretion) on the use of SPE nor do we expect a positive effect of CEO education (interpreted as CEO awareness of common practices) on their use.

Rather, we argue (and provide evidence) for a moderating role of these two observable CEO characteristics on the relationship between iLOC and SPE. Our theoretical argument here again builds on the interpretation of CEO ownership as a measure of CEO discretion and we argue that higher discretion gives personality more room, whereas CEO education is interpreted as a "constraining" mechanism which attenuates the influence of psychological characteristics on strategic administrative decisions in general (and the use of SPE in particular).

Thus, we propose (and provide evidence) that firms with CEOs who are also owners of their companies make lower use of OPE while such firms make relatively high use of SPE when their CEO has a high iLOC. Firms with CEOs with a higher level of education make higher use of OPE while the level of SPE use is relatively unaffected by their CEO's iLOC.

Overall, our research underlines the importance of chief executive personality in relatively small firms and it is a first step towards "CEO psychological characteristics"-based explanations of the particularities of administrative choices in relatively small firms.

The empirical evidence we provide in this paper is subject to a number of limitations and more comprehensive empirical testing of the the possible impact of CEO psychological characteristics on the use of management control mechanisms seems a fruitful avenue for future research. As indicated by the existing literature from psychology and management/accounting (see our above discussion of previous literature), such characteristics should include CEO narcissism, CEO conscientiousness and CEO agreeableness. Moreover, a theoretical and empirical analysis of the joint impact of different aspects of personality and organizational contingencies seems a promising task. In particular, our extensive pretest led us to simplify several constructs of organizational contingencies in an attempt to increase the likelihood of a satisfactory response rate. It is not clear how robust our results on the influence of iLOC on the use of SPE are when employing more comprehensive measures for various organizational contingencies and how psychological characteristics might interact with organizational contingencies in explaining the use of performance evaluations.

Our argument in $\mathrm{H} 1 \mathrm{a}$ and $\mathrm{H} 2 \mathrm{~b}$ is about the $\mathrm{CEO}$ having ownership rights or the CEO being a "professional outside manager" without any ownership rights. Therefore, we asked CEOs whether they possess ownership rights or not. However, we do not measure the degree to which the CEO possesses ownership rights which is again a limitation of our study. Another concern relates to our measure of CEO edu- 
cation. As noted by Hambrick and Mason (1984), education is a crude and muddied measure that includes various aspects related to cognitive style, motivation, socioeconomic background and various other aspects of personality. Clearly, our measure of CEO education (which simply measures if the CEO has a University degree) is extremely crude and cleaner measures of the included aspects of CEO background would be desirable. Moreover, even in small firms, the use of performance evaluations for middle managers is not always made autonomously by the CEO and thus it might be desirable to include also the influence of other top managers (and of their personality characteristics).

In line with great parts of previous contingency research, we model objective and subjective performance evaluation as distinct choices (our empirical analysis uses two different models with OPE/SPE as dependent variables), although these choices may be interrelated as substitutes or complements (and, of course, they may also be related to other control choices). Clearly, a more comprehensive analysis of the influence of executives' personality on choices on control packages would be desirable.

Finally, a quite fundamental issue in cross-sectional upper echelons research is the inability to picture clear cause and effect relationships. Most likely, certain types of firms attract certain types of CEOs and organizational design variables may thus not be the result of CEO personal characteristics but these personal characteristics may rather be implied by organizations hiring CEOs that fit the organization.

Open access funding provided by Vienna University of Economics and Business (WU).

Open Access This article is distributed under the terms of the Creative Commons Attribution 4.0 International License (http://creativecommons.org/licenses/by/4.0/), which permits unrestricted use, distribution, and reproduction in any medium, provided you give appropriate credit to the original author(s) and the source, provide a link to the Creative Commons license, and indicate if changes were made.

\section{Appendix}

\section{SPE - Subjective Performance Evaluation}

Middle managers are evaluated based on my assessment of ... (1 does not apply, 7 applies fully). 


\begin{tabular}{ll}
\hline Item & Factor loadings \\
\hline$\ldots$ the quality of their work results & 0.699 \\
$\ldots$ their work motivation and commitment & 0.852 \\
$\ldots$ their ability to work in teams & 0.826 \\
$\ldots$ their ability to effectively acquire new skills (learning ability) & 0.774 \\
$\ldots$ their long-term perspective on the business objectives & 0.792 \\
$\ldots$ their loyalty towards the company & 0.829 \\
$\ldots$ their identification with the goals and values of the company & 0.801 \\
\hline
\end{tabular}

(Cronbach Alpha:0.900)

\section{OPE - Objective Performance Evaluation}

Middle managers are evaluated based on ... (1 does not apply, 7 applies fully).

\begin{tabular}{ll}
\hline Item & Factor loadings \\
\hline$\ldots$ the achievement of ex ante determined objectives (e.g. revenues, profit) & 0.893 \\
$\ldots$ financial performance measures & 0.897 \\
$\ldots$ non-financial performance measures (i. e. customer satisfaction, reject & 0.531 \\
rate) & \\
\hline Cronbach Alpha:0.685)
\end{tabular}

(Cronbach Alpha:0.685)

\section{iLOC - Internal Locus of Control}

To what extent do you personally agree with the following statements? (1 disagree, 7 totally agree).

\begin{tabular}{ll}
\hline Item & Factor loadings \\
\hline It is mainly dependent on me and my competences whether or not I possess & 0.661 \\
a leading position within a group & 0.717 \\
When I make plans I am sure that my plans become reality & 0.763 \\
I am able to determine a lot of what happens in my life by myself & 0.588 \\
Normally I can represent all my interests by myself & 0.492 \\
Whether or not I have a car accident depends mainly on my driving talent &
\end{tabular}

(Cronbach Alpha: 0.625) 


\section{Strategic Orientation}

We intent mainly to be better than our competitors by ... (1 does not apply, 7 applies fully).

\begin{tabular}{ll}
\hline Item & Factor loadings \\
\hline$\ldots$ achieving lower cost & 0.747 \\
$\ldots$. making services/procedures more cost efficient & 0.841 \\
$\ldots$ improving the utilization of available equipment and facilities & 0.866 \\
\hline
\end{tabular}

(Cronbach Alpha: 0.727)

\section{Outcome Measurability, Task Programmability}

To what extent do the following statements describe your organization?

\begin{tabular}{ll}
\hline Item & Factor loadings \\
\hline It is difficult to measure the performance of middle managers with perfor- & - \\
mance indicators & - \\
It is difficult to assess which actions middle managers have to take to & - \\
achieve certain results & \\
\hline
\end{tabular}

\section{Environmental Uncertainty}

How do you assess the predictability of changes in the following areas? (1 not predictable, 7 very well predictable).

\begin{tabular}{ll}
\hline Item & Factor loadings \\
\hline Behavior and buying patterns of customers & 0.725 \\
Behavior/strategies of competitors & 0.741 \\
Technological developments in your company's primary industry & 0.788 \\
Behavior/strategies of your suppliers & 0.762 \\
\hline
\end{tabular}

(Cronbach Alpha: 0.747)

\section{References}

Abernethy, M.A., J. Bouwens, and L. van Lent. 2010. Leadership and control system design. Management Accounting Research 21(1):2-16.

Armstrong, J.S., and T.S. Overton. 1977. Estimating nonresponse bias in mail surveys. Journal of Marketing Research 14(3):396-402.

Auzair, S.M., and K. Langfield-Smith. 2005. The effect of service process type, business strategy and life cycle stage on bureaucratic MCS in service organizations. Management Accounting Research 16(4):399-421.

Bamber, L.S., J.X. Jiang, and I.W. Yang. 2010. What's My style? The influence of top managers on voluntary corporate financial disclosure. The Accounting Review 85:1131-1162. 
Bernardin, H.J., D.K. Cooke, and P. Villanova. 2000. Conscientiousness and agreeableness as predictors of rating leniency. Journal of Applied Psychology 85:232-236.

Bol, J.C. 2008. Subjectivity in compensation contracting. Journal of Accounting Literature 27:1-32.

Boone, C., B. DeBrabander, and A. Van Witteloostuijn. 1996. CEO locus of control and small firm performance: An integrative framework and empirical test. Journal of Management Studies 33:667-699.

Brownell, P. 1981. Participation in budgeting, locus of control and organizational effectiveness. The Accounting Review 56:844-860.

Brownell, P. 1982. A field study examination of budgetary participation and locus of control. The Accounting Review 57:766-777.

Burkert, M., and R. Lueg. 2013. Differences in the sophistication of value-based management: The role of top executives. Management Accounting Research 24(1):3-22.

Calori, R., G. Johnson, and P. Sarnin. 1994. CEOs' cognitive maps and the scope of the organization. Strategic Management Journal 15(6):437-457.

Carpenter, M.A., M.A. Geletkanycz, and W.G. Sanders. 2004. Upper echelons research revisited: Antecedents, elements, and consequences of top management team composition. Journal of Management 30:749-778.

Celly, K.S., and G.L. Frazier. 1996. Outcome-based and behavior-based coordination efforts in channel relationships. Journal of Marketing Research 33(2):200-210.

Chatterjee, A., and D.C. Hambrick. 2007. It's all about me: Narcissistic chief executive officers and their effects on company strategy and performance. Administrative Science Quarterly 52:351-386.

Chenhall, R.H. 2003. Management control systems design within its organizational context: Findings from contingency-based research and directions for the future. Accounting, Organizations and Society 28(2-3):127-168.

Chenhall, R.H., and K. Langfield-Smith. 1998. The relationship between strategic priorities, management techniques and management accounting: An empirical investigation using a systems approach. Accounting, Organizations and Society 23(3):243-264.

Chin, M.K., D.C. Hambrick, and L.K. Trevino. 2013. Political ideologies of CEOs: illustrative evidence of the influence of executive values on corporate social responsibility. Administrative Science Quarterly 58(2):197-232.

Cooper, W.H., and M.J. Withey. 2009. The strong situation hypothesis. Personality and Social Psychology Review 13:62-72.

Crossland, C., J. Zyung, N.J. Hiller, and D.C. Hambrick. 2014. CEO career variety: Effects on firm-level strategic and social novelty. Academy of Management Journal 57:652-674.

Daily, C.M., and M.J. Dollinger. 1992. An empirical examination of ownership structure in family and professionally managed firms. Family Business Review 5(2):117-136.

Derue, D.S., J.F. Nahrgang, N. Wellman, and S.E. Humphrey. 2011. Trait and behavioral theories of leadership: An integration and Meta-analytic test of their relative validity. Personnel Psychology 64:7-52.

Finkelstein, S., and M.A. Peteraf. 2007. Managerial activities: A missing link in managerial discretion theory. Strategic Organization 5(3):237-248.

Finkelstein, S., D.C. Hambrick, and A. Cannella Jr. 2009. Strategic leadership, theory and research on executives, top management teams, and boards. New York, NY: Oxford University Press.

Ge, W., D. Matsumoto, and J.L. Zhang. 2011. Do CFO's have style? An Empirical Investigation of the Effect of Individual CFO's on Accounting Practices. Contemporary Accounting Research 28:1141-1179.

Gibbs, M., K.A. Merchant, W.A. Van der Stede, and M.E. Vargus. 2004. Determinants and effects of subjectivity in incentives. The Accounting Review 79(2):409-436.

Goldberg, L.R. 1992. The development of markers for the Big 5 factor structure. Psychological Assessment 4:26-42.

Grabner, I. 2014. Incentive system design in creativity-dependent firms. The Accounting Review 89(5): 1729-1750.

Grabner, I., and G. Speckbacher. 2016. The cost of creativity: A control perspective. Accounting, Organizations and Society 48:31-42.

Hall, M. 2016. Realising the richness of psychology theory in contingency-based management accounting research. Management Accounting Research 31:63-74.

Hambrick, D.C. 2007. Upper echelons theory: An update. Academy of Management Review 32(2):334-343.

Hambrick, D.C., and S. Finkelstein. 1987. Managerial discretion: A bridge between polar views of organizational outcomes. Research in Organizational Behavior 9:369-406.

Hambrick, D.C., and P.A. Mason. 1984. Upper echelons: The organization as a reflection of its top managers. Academy of Management Review 9:193-206. 
Hambrick, D.C., S. Finkelstein, and A.C. Mooney. 2005. Executive job demands: New insights for explaining strategic decisions and leader behaviors. The Academy of Management Review 30(3):472-491.

Handler, W.C. 1989. Methodological issues and considerations in studying family business. Family Business Review 1(4):257-276.

Harris, D., J.L. Martinez, and J.L. Ward. 1994. Is strategy different for the family owned businesses? Family Business Review 7(2):159-176.

Hartmann, F., D. Naranjo-Gil, and P. Perego. 2010. The effects of leadership styles and use of performance measures on managerial work-related attitudes. European Accounting Review 19(2):275-310.

Herrmann, P., and S. Nadkarni. 2014. Managing strategic change: The duality of CEO personality. Strategic Management Journal 35:1318-1342.

Hiebl, M. 2014. Upper echelons theory in management accounting and control research. Journal of Management Control 24(3):223-240.

Hiebl, M., C. Duller, B. Feldbauer-Durstmüller, and P. Ulrich. 2015. Family influence and management accounting usage - findings from germany and austria. Schmalenbach Business Review 67(3):368-404.

Hiller, N.J., and D.C. Hambrick. 2005. Conceptualizing executive hubris: The role of (hyper-) core selfevaluations in strategic decision-making. Strategic Management Journal 26(4):297-319.

Hodgkinson, G.P. 1992. Development and validation of the strategic locus of control scale. Strategic Management Journal 13(4):311-317.

Hoffman, D.L., T.P. Novak, and A.E. Schlosser. 2003. Locus of control, web use, and consumer attitudes toward Internet regulation. Journal of Public Policy \& Marketing 22(1):41-57.

Ittner, C.D., D.F. Larcker, and M.W. Meyer. 2003. Subjectivity and the weighting of performance measures: Evidence from a balanced scorecard. The Accounting Review 78(3):725-758.

Janssen, O. 2001. Fairness perceptions as a moderator in the Curvilinear relationships between job demands, and job performance and job satisfaction. Academy of Management Journal 44(5):1039-1050.

Judge, T.A., C.J. Thoresen, V. Pucik, and T.M. Welbourne. 1999. Managerial coping with organizational change: A dispositional perspective. Journal of Applied Psychology 84(1):107-122.

Karasek Jr., R.A. 1979. Job demands, job decision latitude, and mental strain: Implications for job redesign. Administrative Science Quarterly 24(2):285-308.

Krampen, G. 1980. IPC Fragebogen zu Kontrollüberzeugungen (Locus of Control). Nürnberg: Verlag für Psychologie. Deutsche Bearbeitung der IPC-Scales von Hanna Levenson.

Levenson, H. 1972. Distinctions within the concept of internal-external control: Development of a new scale. Proceedings of the Annual Convention of the American Psychological Association 7(1):261-262.

Lied, T.R., and R.D. Pritchard. 1976. Relationships between personality variables and compo-nents of the expectancy-valence model. Journal of Applied Psychology 61(4):463-467.

Lavia López, O., and M.R.W. Hiebl. 2015. Management accounting in small and medium-sized enterprises - current knowledge and avenues for further research. Journal of Management Accounting Research 27(1):81-119.

Miller, D., M.F.R. Kets de Vries, and J.-M. Toulouse. 1982. Top executive locus of control and its relationship to strategy-making, structure, and environment. Academy of Management Journal 25:237-253.

Mintzberg, H., and J. Waters. 1982. Tracking strategy in an entrepreneurial firm. Academy of Management Journal 25(3):465-499.

Mischel, W. 1977. The interaction of person and situation. In Personality at the crossroads: Current issues in interactional psychology, ed. D. Magnusson, N.S. Endler, 333-352. Hillsdale, NJ: Lawrence Erlbaum Associates.

Mitchell, S. 2000. American generations - Who they are. How they live. What they think, 3rd edn., Ithaca, N.Y.: New Strategic Publications, Inc.

Moers, F. 2005. Discretion and bias in performance evaluation: The impact of diversity and subjectivity. Accounting, Organizations and Society 30(1):67-80.

Moers, F. 2006. Performance measure properties and delegation. The Accounting Review 81(4):897-924.

Naranjo-Gil, D., and F. Hartmann. 2007. How CEOs use management information systems for strategy implementation in hospitals. Health Policy 81(1):29-41.

Okhomina, D. 2010a. Entrepreneurial postures and psychological traits: the sociological in-fluences of education and environment. Research in Higher Education Journal 8:1-20.

Okhomina, D. 2010b. Does level of education influence psychological traits? Journal of Management and Marketing Research 3:1-14.

Papadakis, V.M., and P. Barwise. 2002. How much do CEOs and top managers matter in strategic decisionmaking? British Journal of Management 13:83-95.

Phares, E.J. 1976. Locus of control. Morristown, NJ: General Learning Press. 
Podsakoff, P.M., S.B. MacKenzie, J.-Y. Lee, and N.P. Podsakoff. 2003. Common method biases in behavioral research: A critical review of the literature and recommended remedies. Journal of Applied Psychology 88(5):879-903.

Prendergast, C. 1993. A Theory of "Yes Men". The American Economic Review 83(4):757-770.

Randall, R., and D. Sharples. 2012. The impact of rater agreeableness and rating context on the evaluation of poor performance. Journal of Occupational and Organizational Psychology 85(1):42-59.

Rotter, J.B. 1954. Social learning and clinical psychology. NY: Prentice-Hall.

Sassi, F., M. Devaux, J. Church, M. Cecchini, and F. Borgonovi. 2009. Education and Obesity in Four OECD Countries. OECD Education Working Papers No. 39, OECD Publishing:1-44, doi:10.1787/ $5 \mathrm{~km} 4 \mathrm{psm} t \mathrm{8zx}-\mathrm{en}$.

Schaeffer, U., and A. Dossi. 2014. Top management impact on management control. Journal of Management Control 24:219-221.

Snell, S.A. 1992. Control theory in strategic human resource management: The mediating effect of administrative information. Academy of Management Journal 35(2):292-327.

Speckbacher, G., and P. Wentges. 2012. The impact of family control on the use of performance measures in strategic target setting and incentive compensation: A research note. Management Accounting Research 23(1):34-46.

Speckbacher, G., J. Bischof, and T. Pfeiffer. 2003. A descriptive analysis on the implementation of balanced scorecards in German-speaking countries. Management Accounting Research 14(4):361-387.

Spector, P.E. 1982. Behavior in organizations as a function of employee's locus of control. Psychological Bulletin 91(3):482-497.

Srinivasan, N., and S. Tikoo. 1992. Effect of locus of control on information search behavior. Advances in Consumer Research 19(1):498-504.

Taylor, M. 2010. Does locus of control predict young adult conflict strategies with Superiors? An examination of control orientation and the organizational communication conflict instrument. North American Journal of Psychology 12(3):445-458.

Waldersee, R., and S. Sheather. 1996. The effects of strategy type on strategy implementation actions. Human Relations 49:105-122.

Ward, J.L. 1988. The special role of strategic planning for family businesses. Family Business Review 1(2):105-117.

Young, S.M., F. Du, K.K. Dworkis, and K.J. Olsen. 2016. It's all about all of us: The rise of narcissism and its implications for management control system research. Journal of Management Accounting Research 28(1):39-55. 